02

\title{
Передача поперечной намагниченности при спин-обменных столкновениях щелочных атомов
}

\author{
(C) С.П. Дмитриев, Н.А. Доватор ", Е.Н. Пестов, В.А. Картошкин, \\ А.И. Окуневич
}

Физико-технический институт им. А.Ф. Иоффре РАН, Санкт-Петербург, Россия

๑ E-mail: nicolai.dovator@mail.ioffe.ru

Поступило в Редакцию 30 января 2018 г.

Описывается эксперимент по наблюдению эффекта переноса спиновой поперечной намагниченности при спин-обменных столкновениях атомов цезия с оптически ориентированными атомами рубидия.

DOI: 10.21883/PJTF.2018.19.46677.17229

Спиновый обмен является одним из эффективных (альтернативных по отношению к оптической накачке) процессов для получения спин-поляризованных атомов [1-3]. Обычно такой механизм спиновой поляризации используется для передачи и регистрации продольной (направленной вдоль постоянного магнитного поля) компоненты атомной намагниченности (см., например, [4-7]). Однако в спин-обменных столкновениях возможна передача и поперечной компоненты намагниченности, возникающей при воздействии переменного резонансного магнитного поля на атомы, участвующие в столкновениях. О такой возможности впервые сообщалось в работе [8], посвященной спиновому обмену между атомами водорода и натрия.

В настоящей работе описывается эксперимент по наблюдению эффекта передачи поперечной атомной намагниченности при спин-обменных столкновениях щелочных атомов: цезия и рубидия.

Была использована двухлучевая схема эксперимента по оптической поляризации атомов [9]. В качестве источников оптического излучения применялись две рубидиевые спектральные лампы с высокочастотным разрядом. При этом излучение одной из ламп направлялось вдоль 
постоянного магнитного поля $B_{0}$ на ячейку, содержащую пары щелочных металлов - цезия и рубидия (естественная смесь изотопов $\left.{ }^{87} \mathrm{Rb}-28 \%,{ }^{85} \mathrm{Rb}-72 \%\right)$ - и в качестве буферного газа неон при давлении 150 Torr. Необходимая для получения оптически ориентированных атомов рубидия циркулярная поляризация накачивающего света обеспечивалась установкой перед ячейкой циркулярного поляризатора. Возбуждение поперечной намагниченности достигалось с помощью воздействия на атомы перпендикулярного (по отношению к $B_{0}$ ) переменного магнитного поля $B_{1}$ с частотой, близкой к ларморовской частоте щелочных атомов. Вторая лампа использовалась для создания поперечного (перпендикулярного $B_{0}$ ) луча света, регистрирующего атомную прецессию. При этом также применялся циркулярный поляризатор, размещаемый перед ячейкой. Следует отметить, что для более эффективной оптической поляризации и ее регистрации (по изменению оптического поглощения ячейкой) использовалась соответственно пара $D_{1}(\lambda=794.7 \mathrm{~nm})$ фильтров, устанавливаемых перед ячейкой. Сигнал атомной прецессии регистрировался в виде изменения поглощения ячейкой излучения второй лампы на ларморовской частоте с помощью фотодетектора, расположенного после ячейки. Для обеспечения необходимой плотности сталкивающихся атомов цезия и рубидия мы использовали подогрев ячейки с помощью горячего воздуха.

Суть эксперимента состояла в следующем. Под воздействием резонансного циркулярно поляризованного излучения происходила оптическая ориентация атомов рубидия. Спин-обменные столкновения этих атомов с атомами цезия приводили к спиновой ориентации последних. При индуцировании переменного магнитного поля с частотой, близкой к частоте магнитного резонанса основного состояния как рубидия, так и цезия, возникала поперечная намагниченность соответствующих атомов. При этом вследствие спинового обмена аналогично [8] должна была происходить передача поперечной намагниченности от щелочных атомов одного сорта (цезия) к атомам другого сорта (рубидия). Практически это означало появление модуляции поглощения поперечного рубидиевого луча света на частоте $\omega_{\mathrm{Cs}}$ при выполнении условий магнитного разонанса для атомов цезия: $\omega_{\mathrm{Cs}}=\gamma_{\mathrm{Cs}} B_{0}$, где $\gamma_{\mathrm{Cs}}-$ гиромагнитное отношение для атомов цезия.

Такой спин-обменный резонансный сигнал мы регистрировали следующим образом. Включалось переменное магнитное поле $B_{1}$ на фик-

Письма в ЖТФ, 2018, том 44, вып. 19 


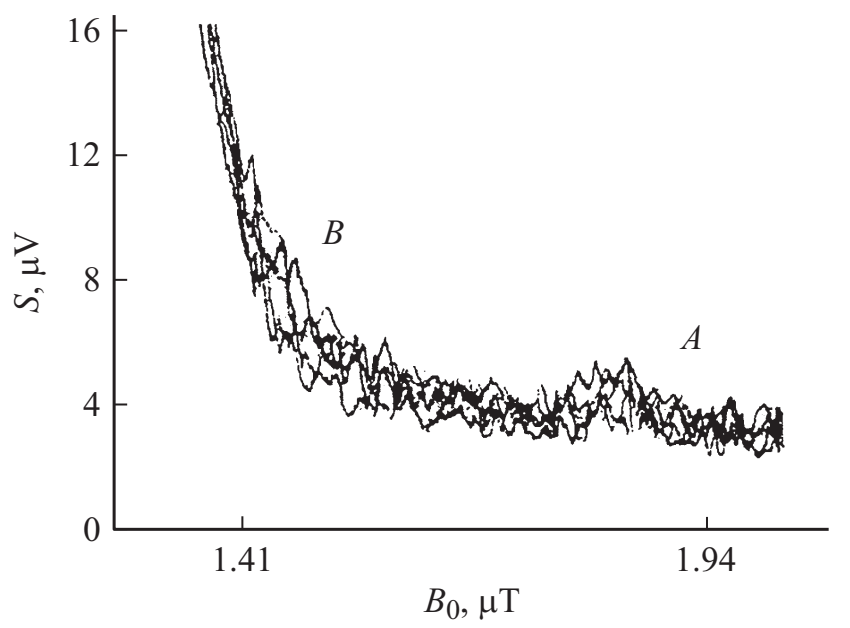

Сигнал переноса поперечной намагниченности атомов цезия, полученный при спин-обменных столкновениях с атомами рубидия $(A)$, и крыло сигнала поперечной намагниченности атомов рубидия $\left({ }^{85} \mathrm{Rb}\right)(B)$, зарегистрированные при четырехкратном сканировании магнитного поля.

сированной стабилизированной частоте $\omega / 2 \pi=6.5 \mathrm{kHz}$ путем подачи напряжения от высокочастотного генератора на кольца Гельмгольца, внутри которых находилась рабочая ячейка. Затем медленно сканировалось продольное магнитное поле путем изменения тока, питающего обмотку соленоида, внутри которого размещалась двухлучевая установка по оптической ориентации атомов. Следует отметить, что с целью уменьшения влияния магнитных лабораторных помех соленоид помещался в четырехслойный цилиндрический магнитный экран с продольным коэффициентом экранирования $K_{s} \sim 10^{3}$. В процессе сканирования тока (в диапазоне $0-1 \mathrm{~mA}$ ) мы последовательно проходили условия магнитного резонанса (МР) для щелочных атомов, обладающих следующими гиромагнитными соотношениями: $\gamma_{87} / 2 \pi=7 \mathrm{~Hz} / \mathrm{nT}$, $\gamma_{85} / 2 \pi=4.67 \mathrm{~Hz} / \mathrm{nT}, \gamma_{133} / 2 \pi=3.5 \mathrm{~Hz} / \mathrm{nT}$. В результате фотоприемник регистрировал резонансное изменение поглощения на частоте $6.5 \mathrm{kHz}$ при значениях тока соленоида, соответствующих значениям индукции постоянного магнитного поля $B_{0}=0.93 \mu \mathrm{T}\left(\mathrm{MP}{ }^{87} \mathrm{Rb}\right), 1.39 \mu \mathrm{T}$

Письма в ЖТФ, 2018, том 44, вып. 19 
$\left(\mathrm{MP}{ }^{85} \mathrm{Rb}\right)$ и $1.86 \mu \mathrm{T}\left(\mathrm{MP}{ }^{133} \mathrm{Cs}\right)$. На рисунке представлен сигнал $(S)$ модуляции поглощения, полученный вблизи значения $B_{0}=1.86 \mu \mathrm{T}$. Следует заметить, что наблюдаемый спин-обменный сигнал оказался чрезвычайно слабым (на несколько порядков меньше, чем сигналы ларморовской прецессии для изотопов рубидия). Его удалось зарегистрировать, применяя малошумящий селективный усилитель и синхронный детектор, подключаемые к нагрузке фотодетектора, работающего в фотодиодном режиме. Кроме того, с целью увеличения скорости спиновых обменных столкновений эксперимент выполнялся при температуре рабочей ячейки $\sim 60^{\circ} \mathrm{C}$, соответствующей плотности атомов цезия $n_{\mathrm{Cs}} \sim 10^{12}$ atom $/ \mathrm{cm}^{3}$.

Слабая величина спин-обменного сигнала в первую очередь связана с „нерезонансной“ природой сигнала вынужденной прецессии атомов рубидия на частоте ларморовской прецессии атомов цезия. Как показано в [8], сигнал, обусловленный передачей поперечной намагниченности при спиновом обмене, должен иметь следующую характерную зависимость: $S_{x} \sim \Delta^{-2}$, где $\Delta=\omega_{\mathrm{Rb}}-\omega_{\mathrm{Cs}}$, а $\omega_{\mathrm{Rb}, \mathrm{Cs}}-$ частоты ларморовской прецессии атомов рубидия и цезия в поле $B_{0}$ соответственно. Отсюда можно сделать вывод, что основной причиной появления спин-обменного сигнала в нашем эксперименте являются столкновения атомов изотопа ${ }^{85} \mathrm{Rb}$ c атомами ${ }^{133} \mathrm{Cs}$. Это прямо следует из того, что частота ларморовской прецессии атомов ${ }^{85} \mathrm{Rb}$ более близка (по сравнению с ларморовской частотой атомов ${ }^{87} \mathrm{Rb}$ ) к ларморовской частоте прецессии атомов ${ }^{133} \mathrm{Cs}$. Кроме того, еще одним из преимуществ спин-обменных столкновений ${ }^{133} \mathrm{Cs}-{ }^{85} \mathrm{Rb}$ (по сравнению со столкновениями $\left.{ }^{133} \mathrm{Cs}-{ }^{87} \mathrm{Rb}\right)$ является то, что в работе использовался рубидий с естественным соотношением изотопов $\left(n_{85} / n_{87}=2.8\right)$.

Необходимо также отметить, что именно фактор частотной расстройки $\Delta=B_{0}\left(\gamma_{\mathrm{Rb}}-\gamma_{\mathrm{Cs}}\right)$ был определяющим при выборе небольшой величины магнитного поля $B_{0} \leq 2 \mu \mathrm{T}$ при постановке описываемого эксперимента.

Таким образом, в работе выполнен эксперимент по наблюдению эффекта передачи поперечной намагниченности при спин-обменных столкновениях щелочных атомов: цезия и рубидия. Дано качественное объяснение особенностей наблюдавшегося спин-обменного сигнала. Предполагается проведение детального теоретического анализа обнаруженного эффекта. 


\section{Список литературы}

[1] Knize R.J., Wu Z., Happer W. // Adv. Atom. Mol. Phys. 1988. V. 24. N 1. P. .223-267.

[2] Walker T.G., Happer W. // Rev. Mod. Phys. 1997. V. 69. N 2. P. 629-642.

[3] Gentile T.R., Nacher P.J., Saam B., Walker T.G. // Rev. Mod. Phys. 2017. V. 89. N 4. P. 045004.

[4] Kartoshkin V, Dmitriev S, Dovator N., Klementiev G. // J. Phys.: Conf. Ser. 2015. V. 635. P. 022042.

[5] Дмитриев С.П., Доватор Н.А., Картошкин В.А., Клементьев Г.В. // Оптика и спектроскопия. 2016. Т. 121. № 5. Р. 689-694.

[6] Chen W.C., Gentile T.R., Walker T.G., Babcock E. // Phys. Rev. A. 2007. V. 75. N 1. P. 013416.

[7] Limes M.E., Sheng D., Romalis M.V. // Phys. Rev. Lett. 2018. V. 120. N 3. P. 033401.

[8] Ruff G.A., Carver T.R. // Phys. Rev. Lett. 1965. V. 15. N 7. P. 282-284.

[9] Померанцев Н.М., Рыжкков В.М., Скрочкий Г.В. Физические основы квантовой магнитометрии. М.: Наука, 1972. 448 с.

Письма в ЖТФ, 2018, том 44, вып. 19 